\title{
El sentido del humor como reflejo del pensamiento crítico y la COVID-19
}

\section{RESUMEN}

\author{
Beder Bocanegra Vilcamango \\ bbocanegra@unprg.edu.pe \\ Universidad César Vallejo \\ Lambayeque-Perú \\ Estudiante de Doctorado \\ ORCID 0000-0002-4157-265X
}

La investigación tiene como objetivo situar el sentido del humor como reflejo del pensamiento crítico en el contexto de la COVID-19, que considera como base cuatro textos publicados en Facebook. En el uso de lenguaje, al ser único, existe la doble interpretación de la realidad y las formas de comunicar los problemas. Al respecto, Hämäläinen (2016) da cuenta de la diferencia del significado literal. Cabedo (2009) señala que no existen dos lenguajes; sin embargo, se manifiestan muchas interpretaciones: una de ellas es el sarcasmo, con el mismo argumento de la crítica como mecanismo de protección social. En esta misma línea, Abad (2015) plantea que el humor permite encarar el miedo. El estudio se basa en la valoración de cuatro textos narrativos breves de 700 palabras, aproximadamente. Las publicaciones recibieron 300 comentarios, 421 likes y se compartieron 183 veces. Una vez realizadas las publicaciones, se analizaron los comentarios, en las que se consideraron las relaciones implícitas y explicitas del sentido del humor con los temas recurrentes en el contexto de la pandemia. Los resultados caracterizan el humor como reflejo del pensamiento crítico y considera el rol implícito y explícito del mensaje.

Palabras Clave: humor, pensamiento crítico, COVID-19 


\title{
A sense of humor as a reflection of critical thinking and COVID-19
}

\begin{abstract}
The research aims to situate the sense of humor as a reflection of critical thinking in the context of COVID-19, which considers as a basis four texts published on Facebook. There is the double interpretation of reality and ways of communicating problems because the use of language is unique. In that regard, Hämäläinen (2016) realizes the difference of the literal meaning. Cabedo (2009) points out that there are no two languages; however, many interpretations are manifested: one of them is sarcasm, with the same argument of criticism as a social protection mechanism. From that point of view, Abad (2015) proposes that humor allows to face fear. The study is based on the evaluation of four short narrative texts of approximately 700 words. The publications received 300 comments, 421 likes and were shared 183 times.

When the publications were produced, the commentaries were analyzed, in which the implicit and explicit relationships of the sense of humor with the recurring themes in the context of the pandemic were considered. The results characterize humor as a reflection of critical thinking and consider the implicit and explicit role of the message.
\end{abstract}

Keywords: humor, critical thinking, COVID-19

Artículo recibido: 27 marzo 2021 Aceptado para publicación: 30 abril 2021 Correspondencia: bbocanegra@unprg.edu.pe Conflictos de Interés: Ninguna que declarar 


\section{INTRODUCCIÓN}

El análisis del humor en el contexto social siempre ha llamado la atención de estudios cuyos aportes constituyen significativos argumentos, incluso hasta la configuración de algunas teorías. Siguiendo la ruta cronológica: Robinson (como se citó en Martín, 2005, p. 33) considera que el humor es la «comunicación, [...] percibida por alguna de las partes como graciosa y la lleva a reírse» o el manifiesto de algunos rasgos de satisfacción. Posteriormente, McGhee (como se citó en Martín, 2005) asume que es «una experiencia mental de descubrimiento y apreciación lúdica de ciertos eventos, ideas o situaciones incongruentes o absurdas» (p. 33). Luego, se asocia con la cognición; por lo tanto, los atisbos para entender el «humor por el humor» no es suficiente.

En todos los procesos sociales, hacer humor es siempre denigrante, porque poco se ha vinculado con la manifestación de la mente humana. Pocos estudios han asociado a grupos de personas; sin embargo, Ziv (como se citó en Martín, 2005, p. 33) considera que «el sentido del humor es una de las características en las parejas ideales y en los profesores ideales». Desde ya el estudio compara comportamientos con privilegios en algunos sectores; en cambio, Simon (como se citó en Martin, 2005, p. 33) profiere que es «una estrategia de afrontamiento basada en la evaluación cognitiva particular de algún estímulo...», con lo cual se aprende a convivir en cualquier escenario, ya sea como emisor o receptor. Es evidente que el humor o cualquier circunstancia humorística es la respuesta taxativa de la naturaleza cognitiva, donde la deducción tiene que ser inmediata; de lo contrario, no genera estado de sosiego, según Martín (2005).

El análisis categorial ha sido el ejercicio más relevante, cuya significación está determinada por el espacio teórico. Desde 1677, con el aporte de Hobbies, la práctica del humor estaba orientada a menospreciar a la sociedad, sin negar la idea de ingenio ni corrección social, mientras que la creatividad fue asociada con ello. El humor es creación de conocimiento, como respuesta cognitiva a las expectativas humanas. Hasta 1928 también está vinculado al juego de diversa naturaleza y a la ambivalencia, porque, según el aporte de Freud, se trata de un proceso de liberación.

La etología humana tiene muchas características que se pueden analizar desde cualquier manifestación social. El desarrollo humano tiene escenarios distintos y antagónicos, que son vistos por todas las ciencias, incluso las que especulan sobre mitos propios de la evolución. Sin embargo, no se advierte que el estado del humor es el producto de los 
procesos cognitivos; por ello, según Robinson (como se citó en Martín, 2005, p. 33), «el humor asimismo tiene ciertos usos frecuentes en el ámbito de la salud que pueden agruparse en aspectos comunicativos, sociales, psicológicos y fisiológicos». El agrupamiento solo explica la naturaleza humana, en tanto se entiende que se trata del pensamiento natural y espontáneo.

\section{ESTRATEGIAS METODOLÓGICAS}

La investigación explica la naturaleza de los cuatro textos publicados en Facebook. No es necesaria la definición cuantitativa, porque la valoración de los datos cualitativos no se sustenta en la medición contable, «ni la expresión del dato de carácter numérico» es prescindible. En la misma línea, se precisa que «el lenguaje utilizado es de carácter discursivo y argumentativo» (Verd, 2016, p. 38). La lógica de la investigación adopta el carácter deductivo y valorativo de 421 likes, que corresponden a usuarios de Facebook, y 300 comentarios con diversos enfoques. Además, se evidencia que las publicaciones se han compartido 183 veces.

Las publicaciones en Facebook han sido periódicas desde el 10 de abril hasta el 16 de agosto de 2020. Cada estructura narrativa no ha superado las 700 palabras, ya que en redes sociales no se lee mucho. Cada texto narrativo es de análisis y está estructurado con ideas presentadas con cierta ironía, pero sin dejar de reflejar la realidad del momento, porque en el discurso se desarrolla el pensamiento crítico con alguna amalgama de sentido del humor, que se acompaña de términos muy coloquiales.

Para definir la caracterización de los textos con abundancia de giros linguiísticos, es necesario precisar que se trata de la «argumentación formal» como estrategia de investigación. Esta corriente propone el formismo en el entendido de que existe una hipótesis del mundo, donde conviven varias especies de objetos y eventos y, por otro lado, se trata del contextualismo, que describe y explica los objetos y eventos en los contextos. White (como se citó en Packer, 2018).

Cada texto está escrito con énfasis en el habla coloquial, muchas veces al servicio del lenguaje hiperbólico, tiene giros lingüísticos viscerales que definen la crítica al comportamiento humano desde el lugar que le corresponde, es decir, si se trata de un ciudadano, autoridad, líder, profesional o no profesional. Algunas características etológicas del comportamiento humano (expectativas, frustraciones, sueños, anhelos, inclusión, exclusión, conectividad, mediocridad, viveza, etc.) se ubican en el marco 
axiológico de cada quien. El comportamiento humano está peligrosamente en el límite de la responsabilidad o la obediencia frente a la COVID-19. El contexto de la cronología es importante en la medida en que ha permitido registrar el comportamiento de los usuarios de Facebook en cada comentario, la idea de compartir la publicación o, sencillamente, registrar me gusta, me encanta, me divierte.

\section{RESULTADOS Y DISCUSIÓN}

El origen de todas las posibilidades tiene la forma del pensamiento y la lógica que la hace proclive a la razón y a las mismas emociones. Por ello, no es difícil afirmar que «el análisis del humor ha sido abordado por numerosas disciplinas, tales como la lingüística, el psicoanálisis, la sociología, la psicología, la publicidad, las relaciones internacionales o la medicina, entre otras» (Casado, 2017, p. 52), porque ha generado argumentos suficientes acerca de la naturaleza humana. La idea de que el sentido del humor es la representación humana no es antagónica o antitética a cualquier tipo de pensamiento, porque el lenguaje ha permitido la comprensión vital de cómo es el hombre cuando ríe o cuando se niega a sonreír. Sin embargo, se advierte que «las personas con buen sentido del humor, son vistas como socialmente más competentes» McGhee (como se citó en Martín, 2005, p. 49). Aun así, parece utópico que la sabiduría pragmática de Piter Albeiro (Colombia), Carlos Alcántara (Perú), Coco Legrand (Chile), Sandy (Bolivia), Cacho Caray (Argentina), entre otros, no tenga los atributos suficientes para pensar que, mediante el humor, se puede ver el mundo sin soslayar el pensamiento crítico.

La variedad de creencias, pese a ser creación humana, niega toda la posibilidad de desarrollo humano, porque la realidad es materia de crítica en un solo plano, como es la misma política o el poder de la economía, pero la pobreza sigue siendo la misma. Como la miseria humana es la manifestación cotidiana. Interpretando a Hegel (como se citó en Martín, 2005), la creación humana es pensamiento que no puede trasladarse sin el lenguaje, es decir, no es posible pensar sin hacer uso del lenguaje, porque el hombre tiene la capacidad, como la ha tenido, de crear conocimiento mediante el sentido del humor. Desde siempre y como cualquier otra manifestación de comunicación, tanto la lengua y el lenguaje fueron y son atributos cuya hegemonía le da sentido al debate sobre la naturaleza humana y su relación con el sentido del humor. Este proceso convergente no ha soslayado el rol de la cognición, sino que ha generado la posibilidad de tener sociedades conectadas, ya que el sentido del humor juega con la palabra y la palabra juega 
al humor; por ello, se conoce el giro lingüístico (Martín, 2005). Desde estas perspectivas, y aquellas que no se mencionan, la recurrencia del cuestionamiento intenta determinar el establecimiento de las relaciones categoriales entre el humor y el pensamiento crítico.

El análisis del humor, con relación al pensamiento crítico, también ha sufrido el embate de la humanidad como factor no aislado al desarrollo humano. El análisis de los antecedentes solo surge cuando se valora el consecuente. Esta relación es contradictoria, pero, al mismo tiempo, es el resquicio para comprender que el humor no solo es el acto provocativo del estado de sosiego: el humor antecede al pensamiento crítico al ser creación humana y solidaria, pero este también precede al humor como respuesta taxativa y relativamente sutil. Esta sinergia ordinal del estado cognitivo, en el que pervive el hombre en relación a la sociedad y enajenada a ella misma, explica que hacer humor no soslaya el pensamiento crítico.

En este contexto, es razonable que el humor sea entendido como «una emoción positiva, que tiene características particulares que hace que una misma situación pueda ser humorística para una persona y ofensiva para otra» Buxman (como se citó en Martín, 2005, p. 46). Por lo tanto, la sociedad es quien decide cómo hacer frente al resto y cómo es que ella misma se autorregula desde la visión del proceso evolutivo.

El sentido del humor tiene un alcance inconmensurable, porque permite «acercar mundos distantes y relacionar objetos diferentes»(Ortiz, 2018, p. 344), con la finalidad de entender que la naturaleza humana es una sola, pero distinta a la vez, porque el humor lo distingue y lo apremia. «El humorismo, por lo tanto, es un procedimiento cuyo fundamento es la contradicción real o aparente entre dos cosas o entre dos ideas». (Hernández, s/f, como se citó en Ortiz, 2018, p. 344). La naturaleza de ser un mecanismo a ultranza lo define como una construcción intelectiva muy prolija, que ayuda al desarrollo humano. En tanto, la idea de procedimiento define el estado social de la humanidad y cómo el sentido del humor da cuenta de cómo es el hombre en cualquier cronología. A continuación, en los siguientes textos, nótese el sentido del humor y el pensamiento crítico en paralelo. Es preciso señalar que la redacción de los cuatro textos presentados a continuación fue precisados para la publicación, ya que en Facebook no era posible realizarlo. 


\section{Coronavirus y homeóstasis ${ }^{1}$}

Antes del bendito 16 de marzo de 2020 se oía que desde la China se culpaba al murciélago, en las redes sociales nos preguntaban si comerse un murciélago es razonable, en la India también dirían que comerse una vaca es razonable. El comportamiento humano se ha comparado con Singapur, precisando que ellos son una sociedad ordenada; este lado del continente no. Los estadísticos se han lucido jugando a las probabilidades, desde luego que Chile fue superior y que Brasil se jugaba la vida. Entre la radio, la televisión y la prensa se ha dicho que la COVID-19 es creación americana para tumbarse la economía de los chinos.

Por otro lado, un buen porcentaje de docentes se traía abajo el programa del Gobierno, algunos desamparados del sentido común, con maestría, cuestionaban que una actriz tenga el privilegio de captar la atención de niños inocentes escribiendo sobre una silla, fotos por doquier. Al mediodía veíamos al presidente Martín Vizcarra emulando al maestro con clara insistencia que la gente se quede en casa; sin embargo, pronto se dijo que lunes, martes y miércoles podían salir solo varones y el resto, mujeres. Las redes sociales deliraron con este anuncio como si fuera la plenitud de la libertad de Zoilo vestido de varón.

En ambos casos los mercados y las entidades bancarias siempre fueron focos de contagio tanto por la misma necesidad o por la torpeza de no entender que lunes, miércoles y viernes solo fueron opciones. Jamás se dijo que es obligatorio comprar esos días indistintamente, pero ganas de jodernos la vida yendo al mercado a comprar camotes para freír o estar parados, como idiotas, leyendo la lista. La sociedad nunca fue consciente que allí el contagio estaba entrando por la nariz por tener la mascarilla de adorno.

[...] de hecho, en la versión de Maslow (1908), la persona desarrolla posibilidades de vida dependiendo de sus necesidades como respirar, alimentarse, descansar, la homeóstasis, etc. Curiosamente, la COVID-19 ataca el sistema respiratorio; sin descubrir que se puede respirar aprendiendo el sentido de la obediencia. ¿Se puede respirar bien con irresponsabilidad? La necesidad de alimentarse está sometida al hábito de comer tres

\footnotetext{
${ }^{1}$ https://www.facebook.com/beder.bocanegravilcamango/posts/2854518551329212.

Esta publicación generó 213 likes, 133 comentarios y se compartió 132 veces. Fue el primer texto publicado a casi un mes de haberse decretado al aislamiento social. La incertidumbre fue total, no se sabía de los mecanismos de protección. Los medios de comunicación tenían su propia versión para encarar el flagelo letal.
} 
veces al día, de allí la necesidad de joder ${ }^{2}$ en el mercado. ¿Se puede vivir comiendo dos veces al día? [...].

Quién podría pensar que Martín Vizcarra, en su implorosa petición para quedarnos en casa, decía que la homeóstasis no ha sido suficiente para controlar la pandemia. Afirmaba que con solo quedarse en casa estaba dando vida a otros inocentes, no necesitábamos colaborar con un sol, solo era quedarnos en casa. Esta irreversible situación solo reflejó que alguna parte de la sociedad no aprende porque la escuela es muy frágil al estar llena de estereotipos. Con un gobernador brabucón, ignorante y resistente, con alcaldes mediocres que no pueden repartir una canasta con víveres solo refleja que la escuela no existió para ellos. Se debe recodar que después de 14 años en las aulas, las personas salen al mercado sin ambiciones, sin proyectos, sin ideas; los expectora sin la capacidad de tomar decisiones, lo expulsa al mundo para que luego no puedan hacer las compras en el mercado, los depone sin haberles hecho temer para que sientan que viviendo el temor una plegaria no es suficiente; es todo lo contrario. Se trataba del cultivo de la obediencia.

En medio de la pandemia ha cobrado sentido el vulgar adagio que siempre ha conducido a pensar que los justos paguen por los pecadores. No es posible que Mesones Muro, ${ }^{3}$ un rinconcito de sol al pie de su mirador, con cero contagiados tenga que ser la fosa común para tantos cadáveres, muchos de ellos inocentes. Los irresponsables tuvieron la oportunidad de arreglar su sala, corral, callejón, dormitorio, etc., pensar en la vida de su familia; sin embargo, se debe decir que la homeóstasis no se produjo en casa, porque no se aprendió en comunidad, tampoco se ha pensado en el bien común.

A pesar de tener el mismo propósito, los dos planos, debidamente caracterizados, evidencian que escribir es distinto a hablar. Por lo tanto, decirlo de modo diferente, pero con el mismo argumento, puede ser ironía o sarcasmo, como producto estrictamente cultural y definido como «un acto de habla indirecta cuyo significado no es el mismo que el significado literal de la oración» (Hämäläinen, 2016, p. 4). La diferencia es la arista que acerca al poder mediante ideas sarcásticas. La sociedad peruana vivió la encerrona y por mucho tiempo el significado establecido fue literal. Sin embargo, las necesidades iban

\footnotetext{
${ }^{2}$ Fastidiar, interrumpir. Manifestación habitual que incomoda, término muy utilizado para comunicar cualquier expresión relativa a los estados emocionales: estoy jodido, está jodida la cosa, todo es jodido, es un jodido, allí todos joden, etc.

${ }^{3}$ Ferreñafe (Lambayeque, Perú) es un distrito progresista. Está ubicado en una zona donde se puede disfrutar del medio ecológico, posee un paisaje natural y muy apacible para vivir. Cuenta con 21100 hectáreas para 4230 habitantes.
} 
construyendo otros significados, que bien pueden ser la fotografía, sin dramas, de la ciudadanía encerrada para hacer escarnio.

A todo esto, se puede identificar el victimario y la víctima con el mismo objetivo, es decir, estar fuera de casa define la condición de víctima y estar en la calle tendría la misma condición por la misma necesidad: ¿quién es la víctima? Este escenario real, pero sostenido por la ironía del lenguaje, funciona estructuralmente como atributo del sarcasmo cuando se refiere a la víctima sin saber quién puede ser. En este sentido, «el sarcasmo siempre requiere una víctima. La víctima no tiene por qué ser el interlocutor, la víctima puede ser cualquier persona o cosa» (Hämäläinen, 2016, p. 4). Tanto el anonimato como el doble ejercicio interpretativo del lenguaje visiona a la víctima como representación humana del buen hacer o del fracaso para utilizarlo sarcásticamente. De cierto modo, las víctimas suelen cosificarse por el mismo proceso social. El desarrollo de la consciencia, al estar encerrados por ley, se aleja del hecho real y se convierte en elemento subyacente a lo irreal.

El juego del lenguaje, que define la realidad social de la pandemia, permitió crear la antítesis a todo pensamiento insurgente a cualquier gesto privativo de la libertad. El presidente peruano tuvo que decir, en el extremo, que ir de compras de forma innecesaria significaba llevar la COVID-19 de yapa. ${ }^{4}$ La realidad oscilante entre la verdad y las formas de decirlo solo asegura que «no existe, por tanto, dos lenguajes, como se propone desde la visión tradicional; esto es, un lenguaje literal y uno figurado, sino dos usos distintos dentro del mismo lenguaje» (Cabedo, 2009, p. 12), que no fue capaz de llegar al consciente y evitar las salidas. El hecho de pervivir dentro de casa representaba la fragilidad que la escuela devuelve. Del discurso logrado en las publicaciones en Facebook, se puede plantear el siguiente testimonio. ${ }^{5}$

Convivir en la pandemia permitió definir que aprender a respirar es aprender a vivir frente a los problemas donde un hombre, una familia, una escuela, el Estado es un sistema que posee disfunción del núcleo de la sociedad en todo nivel, además la falta de conciencia y sentido común permitió que la pandemia le quite el maquillaje a la educación de un pueblo donde la ignorancia es superior a la razón y al mismo tiempo se

\footnotetext{
${ }^{4}$ Porción adicional al producto que se compra. Representa el gesto benevolente del vendedor hacia el cliente. Se tiene por costumbre solicitarla a modo de broma.

${ }^{5}$ Texto elaborado con base en los comentarios publicados en Facebook. Los textos en cursiva no nos pertenecen.
} 
trata de la cultura propia que tenemos donde, al parecer, la desobediencia y mala formación son típicos comportamientos.

De este modo, el juego entre la verdad y el sarcasmo no deja de comunicar el nivel absoluto de la misma ironía, porque el ser humano, lejos de sobrevivir, piensa siempre en protegerse hasta de sí mismo. Por lo tanto, es tan válido como el sentido ético de quien juega con una broma o ironiza la verdad, ya que «el sarcasmo es un mecanismo que salvaguarda, de algún modo, la imagen social del hablante en un ámbito de familiaridad o de amistad. Con ella se evita la brusquedad del pensamiento explícito» (Cabedo, 2009, p. 14). La yapa del presidente o del cliente, sin rima obsecuente, no era la búsqueda de la protección humana. El humor, al ser el reflejo exacto y taxativo del pensamiento crítico, genera expectativas no aisladas o marginales a la intención de la crítica, porque el sentido del humor, pese a ser anónimo, es la construcción dialéctica de la moral, cuyo eufemismo oculta la verdad que, muchas veces, no se evita comprender.

\section{Coronavirus, la pizarra y los profesores ${ }^{6}$}

Siguiendo los talones de Martincito y dejando de lado la gracia inmune de «El Chete» ${ }^{7}$ surgieron algunas ideas en torno al hacer diario de los docentes oyendo «El baile de los que sobran ${ }^{8}$ porque de un momento a otro dejaron la pizarra acrílica y las aulas decoradas con la zona de higiene personal para decirlo, tantas veces, por la pantalla de celular, de TV o del procesador que deben lavarse las manos no menos de veinte segundos, pero los que no tienen agua que se imaginen la escena. La pizarra de cemento se había quedado cansada de tragarse las amígdalas de los profes que utilizaban tizas de colores. Pronto se incorporó la fórmica cuya recurrencia siempre fue material para fabricar mesas brillantes, algunos colegios habían decorado su espacio con el $50 \%$ de pizarra conductista, el otro $50 \%$ con la pizarra constructivista y entre dedos había tres plumones recargados para

\footnotetext{
6 https://www.facebook.com/beder.bocanegravilcamango/posts/3065559053558493. Esta publicación logró 84 likes, 61 comentarios y se compartió en 13 oportunidades. En cuanto al término muy usual, existen diversas manifestaciones: profe, prosor. Esta última alocución es muy recurrente de un cuasi apócope forzado de la palabra profesor. De modo general, se utiliza en la escuela y relativamente en la universidad. En Amazonas, el uso del vocablo profito es muy acentuado y denota un gesto de cortesía, respeto, cariño, estima y confianza.

${ }^{7}$ Indigente de la ciudad de Chiclayo. Su condición lo convirtió en el ciudadano sin razón que ha desarrollado la capacidad inmunológica a la covid-19. Fue muy recurrente cruzarse por las calles convulsionadas por gente que le urgía cobrar el bono de S/380. Personaje reconocido, porque, pese a su demencia, es un individuo nada ofensivo, encerrado en un razonamiento vinculado a un desagradable hecho personal.

${ }^{8}$ Canción emblemática de Los Prisioneros de Chile.
} 
dibujar cuerpos unicelulares sin imaginarse que la COVID-19 estaría entrando sigilosamente $[\ldots]$

Al amanecer el 16 de marzo se pensó que se trataba de una cuestión de días y que Martincito estaba dispuesto a regalar bonos a diestra y siniestra, ahora se le ha ocurrido subsidiar los servicios básicos a miles de familias que no tienen dinero para ello pero tienen el televisor encendido todo el día esperando las cifras de muertos y enterarse que a «Esto es Guerra» ${ }^{9}$ le han regalado algunos millones, pobrecitos. En realidad, debe girar el cheque, con el visto bueno de Swing, ${ }^{10}$ a las empresas antes de generar espantosos conglomerados para pagar el servicio. Precisamente, a los pocos días los docentes estaban conminados a no salir de casa para encarar el ejercicio frente a la pantalla cojuda ${ }^{11}$ cuya frivolidad estaba negando la satisfacción de mi sarcasmo.

De pronto la televisión modelaba sesiones a través del programa «Aprendo en casa» ${ }^{12} \mathrm{y}$ el Ministerio de Educación exigía informes diarios para joderle la vida al prosor como si no tuviera familia que atender. A todo esto, el Blackboard, el Zoom y el Meet habían ingresado para negar la idea de escribir sobre la fórmica de colegio vanguardista. Desde ese día el docente no podía escribir como de costumbre porque sus dedos se habían recogido por naturaleza de zombi a expensas de sus propias emociones encerrado en su propia casa mirando la misma mesa de la cena cubierta con documentos de entrega remota. Más allá, los gritos de su criatura necesitan de su atención, a un costado los hijos mayores mirando la pequeña laptop para ver quién la utilizará primero y el esposo con el dorso desnudo mirando «la gente pasar», entre cajones, a la fosa común sin ser parte de la estadística.

Aquel prosor o prosora perdió la noción del tiempo y espacio, perdió toda sintonía con la empatía pero el corajudo cargado de valor incólume y erguido encara su decisión al ver cada mensaje o llamada de sus alumnitos ${ }^{13}$ que no entienden la indicación en el

\footnotetext{
${ }^{9}$ Programa de televisión que recibió el rechazo de miles de personas porque el Estado le otorgó apoyo económico mediante el programa Reactiva Perú.

${ }^{10}$ Personaje pintoresco y ridículo que causó revuelo en la política peruana, marcó el inicio del pedido de vacancia del presidente Martin Vizcarra.

${ }^{11}$ En Bolivia, Chile, Ecuador, Honduras, México y Perú el término es relativo a 'tonto, bobo'; sin embargo, tiene múltiples acepciones coloquiales, como viste al cojudo ese, es bien cojudo, nadie le gana, es más cojudo que... Igualmente, se ha personificado, por ejemplo, se cayó la pared cojuda, la tarjeta cojuda se quedó en el cajero, etc.

12 Programa educativo que reemplazó a los docentes, cuyo inicio fue dramático porque los animadores fueron modelos, se convirtió en una afrenta a los docentes peruanos.

${ }^{13}$ Término que hace referencia al estado emocional de los escolares. Con frecuencia lo define como un escolar con ciertas carencias. También es un gesto de afecto y cariño de los docentes
} 
WhatsApp. Empieza su día entre la incertidumbre, para algunos, la $\mathrm{ONP}^{14}$ existe, la AFP es un consuelo para otros, la Derrama ${ }^{15}$ pende de un milagro para muchos, el bono cojudo no llega y la COVID-19 tampoco asoma al congreso para desaparecerlo con todo palacio fantoche.

Desperdigado estará el profe, la profe, la miss, el prosor o como se quiera llamar, allí estará el hombre que un día dejó la pizarra por una pantalla, que perdió sus megas, que perdió el control, pero ganó ecuanimidad, allí está la profe que no renuncia a la interacción remota, allí pervive para dar el ejemplo. Allí está el prosor que aprendió a convivir con lo incierto, que aprendió de sí mismo. Allí está el paradigma soportando, acorralado, la trifulca miserable y pestilente que solo exige y nada otorga, que solo pide estentóreamente y no extiende la mano, como si fuera mármol acerado inerte y reluciente, Allí está el maestro rendido al ímpetu, recae, se levanta, abre los ojos, despierta el consciente, mira su entorno, la tristeza lo había callado, la tv lo había sustituido miserablemente por el placer de la actuación. El profe se había ido a tomar un poco de aire para volverse energía, volverse verbo, volverse unísono y garboso frente a las expectativas.

Este texto también sirvió para el sarcasmo de cualquier intención, porque permitió reflejarse de otro modo, y no solo fue el vértigo de la muerte a causa del virus. El humor puede verse con los ojos que quieren observar el ángulo que motiva la reflexión, puesto que se trata del «espacio valorativo de la ideología, en donde el humor responde tanto como estrategia discursiva como transgresora de un poder» (Acosta, 2019, p. 31). Nunca se supo quién tenía el poder, porque el sentido crítico estaba detrás de la mascarilla que se vendía en cualquier esquina; no obstante, los medios de comunicación y su poder generaban más miedo que el mismo virus.

Las posibilidades para analizar el recorrido de los hechos permite repensar que la realidad, en el contexto de la COVID-19, es el insumo perfecto para el humor, bajo la perspectiva de ser «una herramienta imprescindible para luchar contra los miedos ni es universal ni responde a reglas estrictas» (Abad, 2015, p. 256). Por lo tanto, la humanidad no es exenta del poder del humor, porque trastoca el orden de la realidad para salir de ella y llegar a la misma. De allí que «la ironía forma parte de la cultura de una sociedad» (Catalá, s.f., p. 131) cada vez más diferente, como si fuera clasificación humana con el sello de libre

\footnotetext{
${ }^{14}$ Oficina Nacional Previsional. Su función es administrar el fondo de pensionistas.

15 Organismo no estatal que reúne al magisterio peruano. Es el receptáculo de pequeños aportes con fines de ahorro. Con el dinero que administra, facilita préstamos a los docentes con altas tasas de interés.
} 
albedrío. Tanto como el desarrollo de la competencia lingüística, la simbiosis entre el sentido de humor y el pensamiento crítico existen, al menos, dos competencias universales que definen el estado de la cognición del individuo. El análisis y síntesis se producen en simultáneo y son concomitantes al fluido del pensamiento. Encarar el sentido del humor con actitud crítica es una opción no necesariamente para reír, aunque se logre el propósito.

\section{Coronavirus en tabletas ${ }^{16}$}

A pocos días que Martín Vizcarra ordene el espantoso encierro, la osadía del programa «Aprendo en casa» apareció en las pantallas ocasionando comentarios de todos los colores. Poco tiempo después, el alucinado ministro de Educación, que recordaba una escena con burócratas de dos o tres universidades privadas, daba cuenta que las 840000 tabletas estaban en proceso de adquisición bajo los mecanismos que salvaguardaban el más mínimo sentido ético y algún resquicio moral. Desde un modesto sillón contemplaba la noticia pero al mismo tiempo imaginaba la ceremonia protocolar a toda la mediocridad alrededor de un objeto electrónico más pequeño que una hoja de papel bond reciclado para fotocopias.

No me cansaba de observar la «propaganda» a la genial idea de que los escolares de la zona rural tengan una tableta como si los pobladores de Urrunaga, Simón Bolívar o Nuevo Mocce $^{17}$ tuvieran todas las condiciones para acceder al programa. Semejante fiasco de trémulas conspiraciones ministeriales para hacer creer que la preocupación por la conectividad sería un detonante con el mismo poder siniestro de la COVID-19. Pero no sería aguafiestas para quitarle la ilusión tanto a los maestros como a los pequeños escolares que viven desperdigados, sin esperanza, sobre su propio futuro; sin embargo, es la bandera para cualquier advenedizo para robar $^{18}$ pantalla con bombos y platillos con alucinados mensajes de solución y por debajo el Excel cambia los precios y condiciones. A todo esto, era natural recurrir a viejas teorías y prevalentes tesoros de la ecuanimidad

\footnotetext{
16 https://www.facebook.com/beder.bocanegravilcamango/posts/3177659979015066. Publicado en el semanario Expresión, a propósito de una edición impresa, tan pronto se restituyeron las actividades propias del rubro. El texto publicado en edición impresa y en las redes logró 75 likes, 33 comentarios y se compartió en 19 oportunidades.

17 Zonas urbanas marginales de Lambayeque que se han convertido en espacios para la migración y no tienen acceso a internet de forma regular.

18 Término muy usual cuando se refiere a la intromisión. Se trata de un acto poco educado, con ánimo de protagonismo.
} 
del maestro cuando trata de encausar el entusiasmo de los escolares que no siempre van a la escuela por aprender o dizque «desarrollar sus competencias» $[\ldots]$.

A nadie le importará si llegan o no porque detrás del telón y entre papeles de escritorio mudo se había tejido el otro yo siniestro del burócrata inútil, incompetente, inmoral y mil veces trivial hasta cuando contesta una llamada y no sabe qué personalidad escoger para ser atento o muy técnico al exigir condiciones de las tabletas. Sin saber que esta recua de funcionarios estaban desarrollando sus propias motivaciones a expensas de los escolares que sí las necesitan y urgente. Pasará la maldita COVID-19 y las tabletas no llegarán y si llegan se guardarán hasta que la espuma del champagne de la esquina esté presente en la entrega oficial; mientras tanto, algunos niños estarán viendo su diploma de egresado sin saber nada de ella, ¿y la motivación? Habría quedado en la semántica de la inverosimilitud.

Es más que evidente, es más que entendible y muy obvio que llegar a ser funcionario dentro de cualquier ministerio es muy sencillo y asequible para salir más gordo con mórbidos deseos de maquillar el buen desempeño. En las redes sociales dejan la bífida y anfíbica lectura del pensamiento marginal para atreverse a crear sensaciones alrededor de una tableta electrónica cuando se sospechaba el negociazo ${ }^{19}$ que no puede negarse mientras, en acto seguido, se acusaba que las arcas financieras del ministro tienen notables diferencias, es que también tuvo su «propia motivación» para decirnos que su programa «Aprendo en casa» vino para quedarse como las tabletas se quedaron con las ganas de llegar a los niños cuyas expectativas una vez más se postergaron, ¿es cierto que la motivación es permanente.

$\mathrm{Si}$ alguna vez los mediocres pensaran que las motivaciones de los escolares es una forma de existir cuando aprende, si alguna vez entendieran que ellos necesitan del docente, tal vez no se cometa groseros y torpes gestos técnicos premunidos de incompetencia por no saber comprar pequeñas tabletas antes que la COVID-19 les arranque algo de ellos, sus ganas de ir a la escuela. Más seguro es que llega Papá Noel desnutrido antes que las tabletas y se regrese con su jo jo jo jo jo.

Fue siempre irónico creer que los escolares de la zona andina no accedían a internet cuando, en realidad y de forma irónica, los de las zonas urbano-marginales tampoco

\footnotetext{
${ }^{19}$ Término que se refiere, con normalidad, a la coima entre funcionarios. De allí derivan expresiones que anclan en el sentido práctico del comportamiento humano: cómo es el negocio, qué tal negocio y negocio redondo aluden al ejercicio coimero.
} 
acceden. El tejido sociocultural de la realidad fue evidente, porque resaltó la ironía de los hechos. Por ello, es tan objetivo que «la ironía debe poseer una triple condición constitutiva: que su tener literal sea semánticamente verosímil, pragmáticamente contradictorio y deseable en el contexto de la enunciación» Migoyo, como se citó en Catalá s/f, p. 134).

El hecho no fue «semánticamente verosímil», porque las tabletas nunca llegaron a su destino. Fue muy evidente que no existe diferencia entre la realidad y el invento, bajo el oscuro comportamiento social, porque la realidad es el insumo, no solo para hacer sorna, sino que el sarcasmo, la misma ironía o el poder del humor, ofrece verosímiles condiciones para ello. Los hechos son concretos; sin embargo, la interpretación no lo es. Por lo tanto, «no hay una correspondencia biunívoca y constante entre las representaciones semánticas abstractas de las oraciones y las interpretaciones concretas de los enunciados» (Moya, 2006, p. 46), porque cada espacio social construye su propia historia, de la mano de las decisiones siniestras o tan nobles para los que tienen muchas necesidades. Tanto el sentido del humor como el pensamiento crítico son dos planos y su sinergia tiene implicancias absolutas en la conducta humana: son opciones sin privilegios o con todas las prerrogativas para ser diferentes.

El sentido del humor es biplánico, en tanto existen propiedades del lenguaje que definen condiciones para la buena comunicación. El sentido del humor es un plano con argumento político y el discurso político es un plano con argumento para el humor.

\section{0 megas de coronavirus ${ }^{20}$}

El aliento aguardentoso de cualquier agio miserable ha trepado por las ventanas hasta los vacíos espacios universitarios, donde un buen número de estudiantes de cualquier universidad nacional acudió para calmar el ímpetu de proseguir una carrera profesional, aunque, a ciencia cierta, no se sabe si al final de la misma tenga éxito. Tal como sucedió con las tabletas que nunca llegaron a los escolares, un chip marca coronavirus se introdujo en el puerto cuyo discurso tartajeado y mediocre lo había anunciado. Nadie contaba que los diminutos aparatos no tenían alcance en los lugares donde los estudiantes se han quedado varados. Bien podría servir como atuendo junto a una verdosa chaquira huesuda pendiente del cuello para expresar amor eterno a la genial idea. El chip de veinte megas,

\footnotetext{
${ }^{20}$ https://www.facebook.com/beder.bocanegravilcamango/posts/3186077628173301. A propósito de las decisiones que se tomaron en la Universidad Nacional Pedro Ruiz Gallo y se terminó sin licenciamiento. Esta publicación logró 73 comentarios, 19 likes y se compartió en 19 oportunidades.
} 
de un clic, se esfumó en la primera clase. Algunos estudiantes aún no tienen activado el servicio.

La empresa, sabiendo que no tiene alcance, no debió meter la mano ${ }^{21}$ en el negro negocio barato cargado de ilusión como en cualquier casa de trato porque son los mismos chips que se regalan en cualquier esquina temeraria en medio de barbijos y protectores faciales que te pintan como soldador improvisado. Estaba por empezar el ciclo 2020-I, en medio de la incertidumbre, junto a la mediocridad y a lado de la balanza para saber el peso y con ello beber la cantidad de gotas de ivermectina mezclada con leche o diluida en agua, si es que hay. Bendita ivermectina que después de beberla no se sabe si, de pronto, emergen hermosos cuernos de robusto toro mancebo. Sin embargo, fuertes y erguidos encararon la muerte como estilizado torero con pantalón pitillo frente al mamífero antes de la primera estocada.

Circunspectos y con muchos ánimos se fueron corriendo a recibir el chip. Extendieron la mano, firmaron el documento dando cuenta que son pobres o extremos pobres ${ }^{22}$, agradecieron y acariciaron el bendito minúsculo objeto cargado de veinte megas de coronavirus que algún retardado burócrata decidió por ellos. La parasita firma de fantoche con sueldo determinó que fuera solo veinte megas repletas de coronavirus más repelente que ivermectina para vacas que solo pueden dar leche en polvo, aunque la vaca Lola siga cantando. Terrible demostración de mostrenco funcionario y lapidario acto de resolutivo dictamen que solo define y caracteriza la inercia brutal que no entiende que cualquier estudiante universitario necesita más que veinte megas. El tecnicismo que presume siniestro academicismo de funcionario en vinagre se olvidó del aprecio y dignidad, dejó de lado el respeto, impuso su procacidad ante el oprobio de inquietos muchachos que perviven en un sistema carente hasta del sentido común. Todo lo cambió por veinte megas atrofiadas y envueltas de mediocridad absoluta. Acúsese de exagerados parágrafos suscritos, dígnese en vestirlos de críticas. Cuando se habla de calidad educativa y la única forma de acceder a la información sin que diminuto metal se active no es suficiente una lámina 20 megas sin saber que muchos estudiantes no tienen equipos de alta gama, con

\footnotetext{
${ }^{21}$ Alude al acto de participar en negocios turbios e ilícitos. En sentido adverso, implica no participar, ya que no tiene competencia para ello. Esta publicación logró 81 likes, cuatro comentarios y se compartió 21 veces.

${ }^{22}$ Categoría que es certificada por la municipalidad de cada jurisdicción, con la finalidad de acceder a los programas sociales que el Gobierno establece. Sin embargo, las cifras estadísticas establecieron serias contradicciones, porque los no pobres también se beneficiaron.
} 
ello el lenguaje enuncia la verdad bajo la descripción ubérrima de la realidad que no puede negarse al poder del sarcasmo o el mismo humor.

El poder de la inercia cerebral ha llegado al límite de la conciencia y el silencio deshumanizador no despierta; se juntaron en la fila para ser obedientes ciegos a la dádiva producto del embuste político. La inercia del chip-20 o el chip de Oliva ${ }^{23}$ es una versión mejorada de la COVID-19 porque es malévola con fuerte dosis de intencionalidad que separa las aspiraciones de cualquier universitario pobre o extremo pobre que no necesitó un chip para serlo. Este estudiante que comparte una papita rellena ${ }^{24}$ cubierta de cremas todo el día en el kiosco no necesitó un chip para ser fiel a sus ideales; sin embargo, el funesto liderazgo y procrastino estilo de funcionario le dijo que solo veinte megas es suficiente para estudiar accediendo a internet. Solo queda llegar a lo mismo, si se compara el gasto en la movilidad no valió la pena exponerse solo por un chip de veinte virulentos megas cuyo vacío es para mirarlo toda la vida. Los veinte megas solo han indicado que la condición de ser pobre y pobre extremo implica ser la burla de cualquier miserable de saco y corbata que decide sin conciencia.

Relacionar las bondades de la papita con el magro momento del chip sirve de plataforma para el sentido de humor, porque muchos estudiantes, y sus propias limitaciones económicas, han desarrollado su capacidad en medio de la pandemia como parte de la vida universitaria. Por ello, «la persona que tiene sentido del humor tiene un alto grado de autoestima, lo que le permite ver sus imperfecciones y no desea sentirse superior a otros» Begoña (como se citó en Siurana 2013, p. 12). Los veinte megas llegaron cargados de espículas y con ganas de tragarse las expectativas.

Los hechos sucedidos fueron la pauta para describir no solo la incertidumbre o los elementos verosímiles, porque se sabe que «el lenguaje no es sólo [solo] descriptivo y, por tanto, no todos los enunciados tienen que ser necesariamente o verdaderos o falsos» (Escandell, 1993, p. 71). En un escenario político, y donde hay necesidades justificadas

\footnotetext{
${ }^{23}$ Calificación que se le otorgó en mérito a la mediocridad del exrector de la Universidad Nacional Pedro Ruiz Gallo. Su gestión condujo a la universidad al descrédito institucional, al negársele el licenciamiento.

${ }^{24}$ Aperitivo breve y de consumo masivo en el Perú. En muchos casos representa el menú del día o sirve de pretexto para una breve reunión de amigos en cualquier lugar modesto, forma parte de la dieta alimenticia. Algunas crónicas sostienen que tiene origen en la cárcel de Huancayo. Inicialmente se preparaba con el queso molido en batán. Otra versión señala que fue una receta de una mujer de Huancayo que brindaba servicio de menú a muchos obreros que construían el tren en condiciones extremas del clima. Precisamente el consuno de papa les garantizaba energía suficiente para las jornadas, de allí que surgió la idea de la papa de la huancaína. Juan Pablo La Torre, Teresa Izquierdo y Jairo Félix coinciden en que es una salsa, es una crema que bien puede acompañar a los fetuchinis.
} 
o no, la verdad puede ser tratada relativamente y la falsedad es insumo para aprovecharse con delicadeza. Véase el siguiente gráfico.

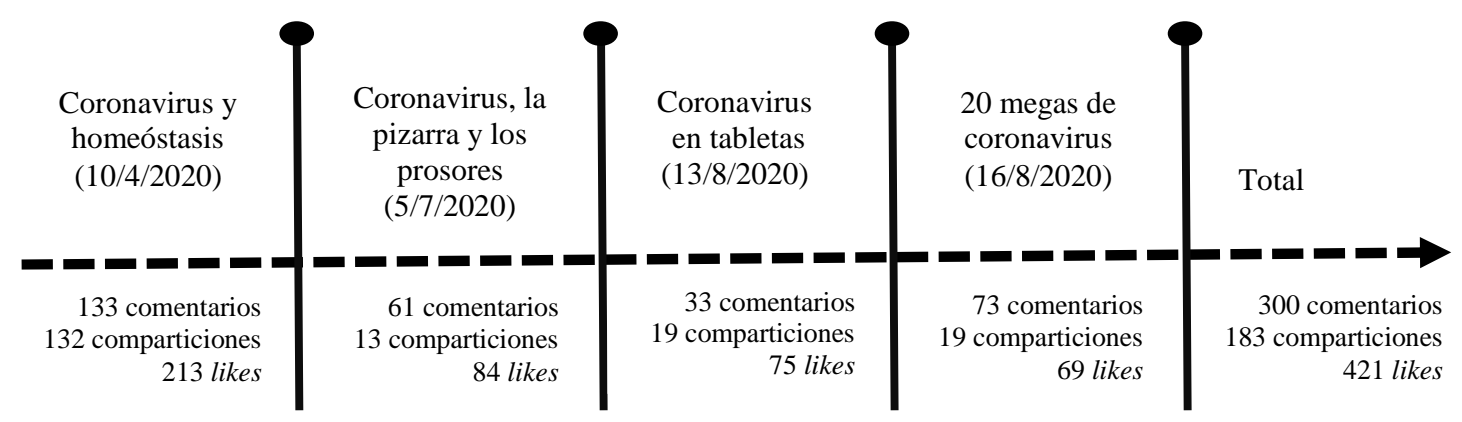

La valoración del humor surge con Hobbes (1677), Fry (1968), Mindess \& Turek (1980) y Ziv (1984), al sostener la «teoría de la superioridad» o menosprecio, cuyo argumento fue lo accidental y la risa como factor de cambio del estado de ánimo. Posteriormente, los estudios de Kant (1791), Schopenhauer (1819) y Goldstein \& McGhee (1972) plantean otra teoría sustentada en «la incoherencia» o incongruencia como factor que puede generar la risa. Los elementos en común cifran las condiciones emocionales de las personas. Sin embargo, Burma (1946), Fry (1968) y Dupont \& Prentice (1988) son parte de otra perspectiva que toma como elemento «la payasada» para definir cierta jerarquía humana.

El poder de la discriminación categorial permite comprender que entre los aportes existe la introducción del pensamiento crítico que marca, de cierto modo, el proceso evolutivo. Por ello, Bergson (1900), Goldstein \& McGhee (1972), Sherman (1988), Buckman (1980) y Ziv (1984) plantean que el humor es «un mecanismo de control». Con ello, la teoría de «la jerarquía» prevalece y es correspondiente con el concepto de superioridad. Por lo tanto, el proceso evolutivo del concepto ha desarrollado ideas con arraigo en el pensamiento crítico. Con este avance, la naturaleza del chiste define «la función social». Es evidente que sobre el sentido del humor ha quedado establecido que el pensamiento crítico es un atributo insoslayable, que precede y antecede con la finalidad de comprender la naturaleza humana.

Posteriormente, Koestler (1964), Goldstein \& McGhee (1972), Ziv (1976) y Papp (1982) asumen una postura más próxima al desarrollo del pensamiento y dejan en claro que se trata de una construcción cognitiva, porque «se trata de una característica de la inteligencia». Este hallazgo importante define el sentido crítico del pensamiento humano 
para no abandonar la idea de superioridad, ya que existe diferencia entre el chiste y la payasada, y ello se convierte en el reflejo del pensamiento crítico.

El registro sigue su curso y Greenwald (1967), Schwartzman (1980), Loy (1982), Buckman (1994) y Apte (1985) deslizan otra idea no menos importante, al asociarla con el acto lúdico de los niños, considerando que se trata de una «estrategia de control de las emociones». Esta idea se sustenta en la «teoría del juego»y, aunque tenga más claro el objeto de estudio, se comprende que el control de las emociones siempre ha sido un espacio muy ligado al control humano como parte de la formación.

En la perspectiva de que el lenguaje tiene más de una interpretación, surge Goldstein \& McGhee (1972) y Keith Spiegel (1972) con la teoría de «la ambivalencia» en el contexto de los sentimientos incompatibles. Finalmente, surge la teoría de «la liberación» de Freud (1928) y Mindess (1980). Estos aportes teóricos caracterizan el proceso evolutivo del humor hacia el pensamiento crítico y la correspondencia muy propia de la humanidad. Se concibe que no existe humor sin pensamiento crítico y que este, a su vez, es el argumento para el humor.

\section{CONCLUSIONES}

El sentido del humor o alguna manifestación que genere estado de sosiego antecede y precede al pensamiento crítico, porque se construye conocimiento y se desarrolla la cognición de manera espontánea. Ambas categorías se retribuyen socialmente para decodificar la naturaleza del aprendizaje antes y después del estado de sosiego.

El lenguaje y el sentido del humor son categorías insoslayables y atemporales, en el sentido de que la autonomía del creador lo utiliza con inteligencia, con el fin de sustentar argumentos en tono eufémico acerca de la realidad. Tanto el humor como el pensamiento crítico es una creación biplánica, que combina indistintamente el plano real y el plano de la creatividad.

El sentido del humor regula las expectativas en cuanto a la valoración de la realidad con la perspectiva crítica. Se produce una simbiosis donde el eufemismo del humor fluye para ejercer el poder de la crítica que induce aprendizaje social.

El sentido del humor representa el análisis y la síntesis como competencias generales e inherentes al individuo; por lo tanto, se trata de reconocer la perspectiva crítica de la realidad como espacio de análisis exante y crítica expost. 


\section{REFERENCIAS}

Acosta, A. (2019). El humor político como discurso para fomentar el control democrático. Revista ComHumanitas. doi: https://doir:org/10.31207/rch.V10il.159

Abad, S. (2015). El humor y sus límites ¿de qué se ha reído la humanidad? Actio Nova: Revista de la Teoría de la Literatura y la Teoría Comparada, 1 (2017), 255-257. doi: https://doir:org/10.15366/actionova2017.1

Cabedo, A. (2009). Análisis y revisión del sarcasmo y la lítote: propuesta de la teoría de la relevancia. Boletín de Filología, tomo XLIV(2), 11-38. Recuperado de https://www.researchgate.net/publication/251068294_Analisis_y_revision_del_s arcasmo_y_la_litote_propuesta_desde_la_Teoria_de_la_Relevancia/link/5523a2 c10cf2f3a40338a488/download

Casado, I. (2017). El humor desde las ciencias sociales. El humor como herramienta de resistencia en movimientos sociales. El Caso del 15M, Periferia. doi: https://dx.doir:org/10.5565/revperiferia.513

Catalá, M. (2001). Ironía, humor inferencia: procesos cognitivos. Tendencias creativas en la publicidad actual. Acciones e Investigaciones Sociales. Recuperado de https://dialnet.unirioja.es/servlet/revista? $\operatorname{codigo}=1586$

Escandell, M. (1993). Introducción a la pragmática. España, Barcelona: Editorial Anthropos. Promat, S. Coop. Ltda.

Hämäläinen, M. (2016). Reconocimiento automático del sarcasmo-esto va a funcionar bien. Recuperado de https://www.researchgate.net/publication/339182029_Reconocimiento_automati co_del_sarcasmo_Esto_va_a_funcionar_bien/link/5e430d3692851c7f7f306dab/ download

Martín, J. (2005). El humor en la práctica de la psicoterapia de orientación sistémica (tesis doctoral). Universidad de Buenos Aires. Recuperado de http://catalogosuba.sisbi.uba.ar/vufind/Record/KOHA-OAI-APS:15975

Moya, C. (2006). Relevancia e Inferencia: Procesos cognitivos propios de la comunicación humana. Forma y Función, (19), 31-46. Recuperado de https://www.redalyc.org/articulo.oa?id=219/21901902 
Ortiz, E. (2018). Estudio exploratorio sobre la utilización del humor en el proceso de enseñanza aprendizaje universitario. Transformación. Recuperado de http://scielo.sld.cu/scielo.php?script=sci_abstract\&pid=S2077

Packer M. (2018). La ciencia de la investigación cualitativa. Colombia: Ediciones Uniandes.

Siurana, J. (2013). Los rasgos de la ética del humor una propuesta a partir de autores contemporáneos. Veritas. Recuperado de https://scielo.conicyt.cl/scielo.php?script=sci_arttext\&pid=S0718$\underline{92732013000200001}$

Verd. J. (2016). Introducción a la investigación cualitativa. España: Editorial Síntesis. 